\title{
EL CÓMIC Y LA ENSEÑANZA DE LA HISTORIA CONTEMPORÁNEA. APUNTES DIDÁCTICOS PARA LA ENSEÑANZA DE LA MEMORIA HISTÓRICA Y LOS MOVIMIENTOS SOCIALES EN DISTINTOS NIVELES EDUCATIVOS
}

Julián Vadillo Muñoz ${ }^{1}$

Universidad Carlos III de Madrid

Recibido 29/03/2021 Aceptado 26/05/2021

\begin{abstract}
Z La amplitud de la historia, en los distintos niveles educativos que se imparte, a veces genera problema a la hora de abarcar su totalidad o hay cuestiones que quedan en un segundo plano. Una cuestión que para el docente se convierte en un problema. Además, las nuevas corrientes historiográficas en el ámbito universitario, como la memoria histórica, hace que los planes de estudio se tengan que adaptar a ello. Una forma sencilla de abordar esas zonas grises en el temario de historia, tanto en primera, secundaria como Universidad, es el cómic. En este artículo se realiza un repaso general al estado de la cuestión de la memoria histórica, de la importancia del cómic en el ámbito educativo y de ejemplos a través de ítems histórico de cómics que pueden servir de adaptación didáctica a las finalidades académicas.
\end{abstract}

5 The breadth of history, at the different levels of education that it is taught, sometimes creates problems when it comes to covering it in its entirety, or there are issues that remain in the background. This becomes a problem for the teacher. In addition, new historiographical trends at university level, such as historical memory, mean that curricula have to adapt to this. A simple way of tackling these grey areas in the history syllabus, both in primary, secondary and university education, is through comics. This article gives a general overview of the state of the question of historical memory, the importance of comics in the field of education and examples of historical items from comics that can be used as didactic adaptations for academic purposes.

DOI

https://doi.org/10.15366/didacticas2021.24.003

PALABRAS CLAVE

Cómic; Memoria histórica; Feminismo; Guerra Civil; Fascismo y antifascismo; franquismo.

KEYWORDS

Comics; Historical memory; Feminism; Civil War; Fascism and antifascism; Francoism. 


\section{INTRODUCCIÓN}

La explicación de la historia no es un proceso fácil, partiendo del concepto de complejidad de cualquier disciplina. El reto que el docente tiene por delante es hacer simple lo complejo y eso abarca todos los estadios educativos: infantil, primaria, secundaria y universitaria.

La gran pregunta que los docentes nos hacemos en estas circunstancias es como se puede alcanzar la explicación simple sin perder nunca la complejidad del proceso. Para eso, tenemos que ir diseñando toda una serie de recursos didácticos que complementen y amplíen nuestras explicaciones teóricas.

Ciertamente, tenemos en la actualidad una gran gama de recursos que permiten hacer esa complementación lo más amplia posible. Desde la utilización de recursos gráficos y de películas, bien a través de videos y DVD como de plataformas digitales de libre acceso como YouTube, o aplicaciones como kahoot que hace que interactúe el juego con la enseñanza. Basándonos en los currículums oficiales, así como siguiendo los criterios marcados de evaluación y estándares de aprendizaje, estas múltiples herramientas han facilitado muchas cuestiones en las distintas etapas educativas. Numerosos proyectos en el campo de las ciencias sociales, han abarcado trabajos con los alumnos que han ido desde la elaboración de blogs didácticos, podcast sobre acontecimientos históricos o elaboración de periódicos a través de aplicaciones que ayudan a diseñarlos.

Eso ha hecho que la enseñanza de la Historia haya sido cada vez más dinámica y nos haya permitido acercar realidades que las clases magistrales o los manuales impiden profundizar.

Aquí se va a trabajar las posibilidades didácticas que para los niveles de primaria, secundaria y universidad puede ofrecer un material como el cómic. Y lo vamos a centrar en algunos aspectos concretos, pues el cómic es variado y puede abarcar muchos aspectos históricos. En este caso lo hemos centrado en la historia contemporánea y, más concretamente, en algunos aspectos de la misma que sirve para complementar y ampliar las explicaciones impartidas en clase. Además, en el caso de la educación secundaria, tanto en la ESO como el Bachillerato, se puede aplicar, por lo materiales aquí expuestos, a la enseñanza bilingüe. Si bien alguno de los materiales que aquí se van a presentar están en francés, existen títulos de sobra para poder aplicarlo al bilingüismo de inglés. Además, esta idea se va a mostrar cómo puede alcanzar a varios grados educativos. El cómic puede ser un buen punto de enganche con el alumnado de la enseñanza primaria, al poder ser más sencillo explicar un acontecimiento histórico a través de una serie de viñetas. Para la secundaria partimos de los niveles educativos donde hay que fomentar de forma abierta la lectura, y el cómic muchas veces se han convertido en un comienzo, o bien, ya en Bachillerato, en la profundización de algunos aspectos. Para los niveles universitarios la profundización y complejidad de la materia hacen del cómic un buen punto de partida. 


\section{MARCO DE LA MEMORIA HISTÓRICA Y DE LOS MOVIMIENTOS SOCIALES CONTEM- PORÁNEOS. SU APLICACIÓN AL AULA}

El concepto de memoria histórica tiene varias acepciones en el vocabulario actual. Por una parte, la memoria histórica es un movimiento social que desde hace décadas viene trabajando por recuperar el pasado traumático provocado por la Guerra Civil y la dictadura franquista, con incursiones en los primeros momentos de la Transición democrática. Aunque este cometido siempre contó con defensores desde los inicios del cambio político en España, en los últimos 25 años se ha producido un desarrollo del movimiento memorialista y asociativo. Un movimiento de carácter ciudadano y civil que ha venido reivindicando a las víctimas de la dictadura y su reconocimiento en el marco de las libertades democráticas.

Por otra parte, la memoria histórica es también un campo de investigación y estudio historiográfico, que ha generado grupos de investigación en distintas universidades españolas. En este contexto, estos grupos de investigación han sido variados y en algunas ocasiones han estado en conexión con el mundo asociativo memorialista. A pesar de ello su campo de estudio se ha centrado en el entorno académico, creando una corriente historiográfica que ha puesto como objeto de estudio básico la Segunda República, la Guerra Civil y la represión franquista.

Ambas cuestiones, no dejan de generar polémicas, por la diversidad de enfoques. Aunque los debates suelen ser enriquecedores a veces han paralizado la propia actividad. (Vadillo Muñoz, 2019: 37-99)

Sin embargo, tenemos una tercera pata de la cuestión de la memoria histórica, que es el componente didáctico, aplicado a las aulas de los diversos niveles educativos. Para esta labor, y en conexión directa con las investigaciones históricas realizadas, se han elaborado un buen número de materiales y unidades didácticas que han posibilitado acometer de forma individual la enseñanza de nuestro pasado traumático.

Podemos destacar algunas de esas guías didácticas, más pensadas para los alumnos de secundaria o de niveles superiores, aunque con una buena adaptación las podríamos aplicar a primaria. En el año 2007, e impulsado por la Fundación de Investigaciones Educativas y Sindicales, el profesor Francisco Flores Tristán realizó unas unidades didácticas sobre la educación en la Segunda República. La composición de las mismas fue muy básica. Se partió de una explicación sencilla de cómo era la educación previa al periodo republicano, como se acometió las reformas republicanas y los avances en el campo educativo, para finalizar con un epílogo donde se muestra el retroceso que en este campo significó el franquismo. En la parte final del cuadernillo introduce unas metodologías y criterios de evaluación perfectamente adaptables a cualquier aula educativa, con algunos textos que pueden servir de soporte y material didáctico (Flores Tristán, 2007). Si bien las actividades no están desarrolladas, si están marcando los pasos para poder hacerlo. A estas unidades les acompañó una exposición, que recaló en diversos centros educativos y sirvió 
como punto de arranque para poder incentivar el realizar unidades didácticas sobre estas cuestiones en los centros.

Siguiendo esa línea de la especificidad, los autores Cristina Escrivá y Rafael Maestre, por encargo de la Fundación Salvador Seguí de la CGT, elaboraron una propuesta didáctica similar a la anterior, pero centrada en las transformaciones revolucionarias que los libertarios impulsaron en la retaguardia republicana desde julio de 1936. A través de pequeñas explicaciones y con un aparato gráfico muy trabajado, se elabora pequeños cuestionarios relacionados con diversas cuestiones de la materia (Cultura libertaria, naturismo, milicias confederales, cine, teatro, pedagogía, etc.). Se llega a hacer una propuesta dirigida al alumnado para rellenar una ficha de historia oral, para contar la historia familiar en relación a los acontecimientos de las unidades trabajadas (Escrivá y Maestre, 2008). Un trabajo didáctico muy completo que acompañaron un CD explicativo y ampliativo para poder poner en marcha estas propuestas.

También de Cristina Escrivá, y encargado por la Asociación Cultural Instituto Obrero, realizó un trabajo similar en relación a las Institutos Obreros, impulsados entre 19361939 en diversos lugares de la retaguardia republicana. Estas propuestas didácticas se elaboraron como parte de una exposición sobre estos Institutos Obreros, que fueron creados por decreto de la República en septiembre de 1936. La unidad está bien estructurada, trasversal a todos los currículos y adaptable a distintos niveles, donde se marcan objetivos pedagógicos y criterios metodológicos (Escrivá, 2009). Con explicaciones sencillas y buen un aparato gráfico, también se acompaña de un glosario, textos y un CD complementario. Siguiendo la línea del anterior sobre la revolución libertaria, también incluye una ficha de trabajo personal del alumno como historia de vida de su familia y los recuerdos, directo o indirectos, de estas experiencias educativas.

Un poco más complejo, pero también muy didáctico y divulgativo, es la obra de Francisco Collado Cerveró titulada Los del monte. Una historia del maquis. Este pequeño libro de historia, que narra la importancia de la guerrilla antifranquista durante los años de plomo de la dictadura, está más pensado para alumnos de Bachillerato o, incluso, de Universidad, como elemento introductorio a la materia y con la posibilidad que ofrece, por su sencillez, de poder elaborar una unidad didáctica relacionada con el maquis (Collado Cerveró, s/f). Aunque el libro es de Collado Cerveró la propuesta didáctica pertenece a Nuria Mestre Marcotegui. Es un ejemplo de cómo abordar un tema apenas tratado en los libros de texto y, además, desgajarlo de la enorme carga peyorativa que la guerrilla antifranquista aún tiene a nivel social. El ejercicio didáctico de ponerlo en conexión con las resistencias antifascistas durante la Segunda Guerra Mundial es eje central para explicar este fenómeno.

Pero es quizá las propuestas de unidades didácticas sobre recuperación de la memoria histórica, desarrollada por los profesores de la Universidad de León Enrique Javier Díez Gutiérrez y Javier Rodríguez González, el proyecto más acabado y pionero en esta línea. Publicadas por el Foro por la Memoria de León en el 2008, los autores centran sus pro- 
puestas en Segundo Bachillerato, dentro de la asignatura de Historia de España. Se desarrollan tres unidades: La Causa Republicana, la represión franquista y la resistencia antifranquista. Todo ello perfectamente al marco jurídico, que por el tiempo que ha pasado habría que adaptarlo. Sin embargo, la metodología de trabajo, la trasversalidad y la atención a la diversidad está perfectamente trabajada, así como los criterios de evaluación. Las explicaciones al respecto de cada ítem marcado con los subepígrafes, se acompaña con un buen aparato de propuestas de actividades, actividades de síntesis, de refuerzo y ampliación, que hacen de este ejemplo uno de los más completo y reflejo para muchos otros (Díez Gutiérrez y Rodríguez González, 2008). Aunque habría que adaptar la normativa legal a actual marco jurídico y aunque están pensadas convenientemente, para Segundo de Bachillerato, se podría adaptar a cualquier otro nivel educativo.

Un último aspecto a destacar en este pequeño estado de la cuestión a nivel de materiales, sería la importancia que para la enseñanza de la historia de España tiene el libro EL bulldozer negro del general Franco, escrito por el profesor de la Universidad Autónoma de Madrid, Fernando Hernández Sánchez. La importancia de este texto para cualquier docente, radica en su propósito. No es un manual de Historia de España, que pudiese ser utilizado en los cursos de secundaria, aunque si se puede aplicar como lectura en las universidades. Lo que si permite, por los recursos que ofrece en sus páginas, es la aplicación de muchas de sus cuestiones a las aulas de primaria, secundaria y universidad. Las aportaciones de interés de este texto son varias. La primera, la forma de explicación de los temas que pretende abordar (crisis de la Restauración, dictadura de Primo de Rivera, Segunda República, Guerra Civil y franquismo). Como establece en sus páginas, la historia de España parte un mal concepto de análisis desde los propios libros de texto. La Segunda República se une irremediablemente con la Guerra Civil, y eso genera una visión en el alumnado de que la causa de la Guerra fue la República:

\footnotetext{
Semejante cronología tiene como consecuencia la generalización de una visión teleológica: la indisoluble unión de Segunda República y guerra civil condena a aquella como preámbulo indefectible de esta. El franquismo, lindante con el fin de la guerra que ejerce una función de parteaguas respecto al periodo anterior, queda encapsulado en su propia temporalidad, ajeno a su origen en y como causante de la guerra civil, como si la dictadura no se hubiese reivindicado hasta el final de sí misma como "el Estado del 18 de julio" (...) (Hernández Sánchez, 2016: 190).
}

Sin embargo, el periodo republicano fue un intento de modernización de la sociedad española, con todos sus problemas estructurales, que fue cortado de súbito por un golpe de Estado que es la causa de la Guerra Civil y de la posterior dictadura. Junto a estas explicaciones que rompe las ideas preconcebidas del periodo tratado, Hernández Sánchez introduce cuestiones que pueden servir como elemento esencial en a la hora de una aplicación didáctica en el aula. Las nuevas tecnologías y las TIC están presentes en la obra a través de códigos QR que nos llevan a páginas web, videos y recursos didácticos que pue- 
den complementar nuestras explicaciones en el aula. Además, incentiva el espíritu crítico, introduciendo un capítulo con una ucronía que partiría de un supuesto triunfo del golpe de Estado del 23 de febrero de 1981, poniendo nuestra imaginación de como habría sido el futuro español. Un ejercicio que podría realizar los alumnos dando distintas visiones.

Por último, la obra, que tiene unos magníficos recursos gráficos complementarios, incluye en cada capítulo un epígrafe llamado "El rincón de los lugares comunes”, donde analiza esos lugares que han nutrido una historia canónica en España, que se han dado por sentado a lo largo del tiempo y que no se corresponde con las investigaciones históricas que se han realizado sobre la época.

Si exponemos estas obras en este momento, es porque todas aplican para su contenido didáctico materiales que no son los clásicos de textos y cuadros explicativos, sino que da más pasos y pone como eje de los aportes educativos los recursos cinematográficos, las TIC y el cómic.

Partiendo de las herramientas innovadoras que nos ofrecen estas unidades didácticas y escritos, lo vamos a vincular con una serie de cómic para complementar y ampliar las tareas del docente a la hora de explicar determinadas cuestiones de la historia universal y de España.

\section{EL CÓMIC APLICADO AL ÁMBITO EDUCATIVO}

No cabe ninguna duda de que una forma de fomentar la lectura desde las primeras edades es el cómic. Aunque su utilización ha sido denostada en muchas ocasiones, al considerarlo una lectura menor o que en realidad no acomete el objetivo marcado, lo cierto es que su lectura se convierta en el arranque de la necesidad de leer.

Aquí no se puede hablar del cómic como factor de inicio a la lectura, pero si como un elemento de carga didáctica que nos puede permitir aproximar algunas realidades históricas. Aunque en el siguiente epígrafe se aplicará cómic con relación a la memoria histórica y el pasado traumático de España, las novelas gráficas también han abordado otros ámbitos de la historia y otras épocas, por lo que el objetivo final es aplicable a cualquiera de ellos.

Existen trabajo de peso que analizan la importancia del cómic en la educación y su aplicación en el aula en distintos niveles educativos. Trabajo de enorme valía son los presentados por Alba Tapia Vélez, como Trabajo Fin de Grado (TFG) en la Facultad de Educación de la Universidad de Cantabria, con el título El cómic como recurso didáctico. Una propuesta interdisciplinar desde la plástica (Tapia Vélez, 2018). Otro es el Trabajo Fin de Máster (TFM) de Elena Arroyo Díaz en la Universidad de Castilla-La Mancha con el título El cómic como recurso didáctico para el estudio de la Historia Contemporánea. Selección de lecturas para ESO y Bachillerato (Arroyo Díaz, 2019). Dos magníficos traba- 
jos que analizan de forma general y con ejemplos particulares la utilización de estos recursos en las aulas de primaria y secundaria.

En la obra coordinada por David F. de Arriba, Gerardo Vilches realiza un interesante y breve recorrido por la historia del cómic centrándolo en distintos espacios geográficos y momentos históricos (Vilches, 2019: 16-29). Algo necesario para ver la evolución de un arte y de una literatura que fue marcando distintas etapas. De una forma sencilla y divulgativa nos lleva por los distintos momentos del cómic, desde los orígenes hasta las actuales novelas gráficas.

En esa evolución hace algunas paradas en España, donde tenemos que realizar algunas consideraciones que nos pueden valer como punto de partida. El cómic en España ha sido utilizado en todas las épocas recientes. Como recurso didáctico ya se puede hacer una parada obligatoria. Por ejemplo, una buena forma de ejemplificar los años de plomo del franquismo, la falta de oportunidades y el hambre, lo puede representar un personaje como Carpanta (Guiral, 2008; Moix, 2007). Este personaje de Escobar vio la luz por primera vez en 1947, años complicados para la historia de España. Aunque no hay correlación aparente, puede que Escobar conociese a Pete the Tramp, un personaje del dibujante Rusell que es un vagabundo en EEUU en los tiempos de la Gran Depresión. Carpanta era un personaje sin oficio ni beneficio que vivía debajo de un puente, aunque con el paso de los capítulos llegó a tener una destartalada casita, y que su único objetivo es conseguir comida. Una forma de poder hacer entender al alumnado aquellos difíciles años del franquismo es a través de un personaje como Carpanta, que no dejaba de ser una muestra de aquella España que luchaba por salir de una situación de miseria en el entorno económico de la autarquía y de la represión de la posguerra.

Otra forma de mostrar el anticomunismo propio del franquismo es a través de la serie de cómic de Hazañas Bélicas, donde a través de una idea muy sesgada de paz se intenta llegar a ella por medio de la guerra. El enemigo básico de aquellas historias en muchas ocasiones eran los comunistas, tanto en la Segunda Guerra Mundial como en conflictos posteriores tales como Guerra de Indochina o la Guerra de Corea:

Es extraño que Hazañas Bélicas pretenda condenar unos hechos sin los cuales no existiría la colección. Las contradicciones aumentan cuando nos damos cuenta de que esta continua apología de la paz se ha puesto casi siempre del favor del más fuerte, condenando a los ojos infantiles a todos aquellos enemigos que no encajaban en la idea de «causa justa» fomentada oficialmente (Moix, 2006: 226)

A pesar de todo, estos cómics no son monolíticos en el tiempo y fueron cambiando a lo largo de su dilatada historia. Algo que no se corresponde por ejemplo con la revista infantil Flechas y Pelayos, en clara referencia a las organizaciones infantiles de carlistas y falangistas, donde en distintas historias reivindican constantemente el contenido imperial de aquel primer franquismo, algo que incluso para estudiosos del tema como Antonio Martín Martínez se volvió anacrónico desde fechas muy tempranas del franquismo (Mar- 
tín Martínez, 1968: 67-68). Una manera de poder ejemplificar como a través de revistas infantiles el franquismo también introducía todo su mensaje y lenguaje dictatorial.

Pero no solo el cómic español más generalista puede valer como elemento didáctico para reforzar o ampliar explicaciones. Un buen ejemplo de ello puede ser dos de los cómics más famosos: Asterix y Tintin. La serie de Asterix se comenzó a editar en 1959 por el guionista René Goscinny y el dibujante Albert Uderzo. Aunque la ubicación cronológica de los acontecimientos tiene lugar en el siglo I antes de nuestra era, en una aldea de la Galia, muchos personajes son trasuntos de personajes históricos y de la época de la Guerra Fría. No deja de ser interesante la forma de afirmación gala por parte de los personajes, en un momento histórico donde Francia buscaba una posición internacional frente al atlantismo de los EEUU y Reino Unido y frente a la Unión Soviética. A largo de los capítulos, aparecen personajes históricos de Bélgica, de Francia, etc., incluso referencias a Napoleón. La resistencia a ultranza contra los romanos no dejaba también de ser entendida como una resistencia al imperialismo. Hay algunos pasajes de algunos de los capítulos que se pueden utilizar como recursos didácticos para hablar de la Guerra Fría o presentar el momento histórico para una asignatura como Historia del Mundo Contemporáneo.

Un caso particular podría ser el del Tintín, que nos puede servir en aula para muchas cuestiones (Laport, 2016). El personaje de Tintín apareció por primera vez en 1929, años antes de inicio de la Segunda Guerra Mundial, y realizada por Georges Remi, más conocido como Hergé. Los inicios de Tintín fueron en la revista Le Petit Vingtième, adscrita al movimiento católico belga y como suplemento de la revista Le Vingtième siècle. Esto determinó las connotaciones ideológicas de los primeros capítulos de Tintín, que como Tintín en el país de los soviets (Tintin au pays des Soviets) o Tintín en el Congo (Tintin au Congo), publicados en 1930 y 1931 marcaban una visión anticomunista y colonialista. A pesar de que en algunos capítulos como Le Sceptre d'Otokkar de 1939, se hace una crítica al Anschluss que había patrocinado la Alemania nazi, lo cierto es que Hergé siempre estuvo con la sospecha de simpatía por el fascismo y por las corrientes del Partido Rexis ta belga encabezado por León Degrelle. También es verdad que el discurso de Hergé se suavizó desde sus primeras tiras con Le Petit Vingtième a cuando comenzó a publicar con Casterman antes y después de la Segunda Guerra Mundial, suavizando incluso los diálogos de capítulos como el del Congo. No es objeto de este artículo analizar la ideología del autor, pero esos primeros capítulos de Hergé si nos sirven a nivel didáctico en el aula para poder introducir el imperialismo y el colonialismo (en el caso del capítulo del Congo) o la Revolución rusa y el nacimiento de la URSS desde la perspectiva de los corresponsales extranjeros en el caso de Tintín en Rusia. No olvidemos que en este último capítulo Tintín, acompañado de Milú, es corresponsal del Le Petit Vingtième.

Es solo un pequeño ejemplo de la utilización de comic generalista o de tirada amplia. Ahora se analizará un cómic más específico en temáticas, más reciente en su elaboración y que puede servir como complemento y ampliación a las explicaciones y actividades de 
materias como Historia del Mundo Contemporánea, Historia de España o a los distintos niveles de primaria. Aquí también entraría las distintas materias de historia universal o historia de España que se imparten las facultades de historia, humanidades o formación del profesorado, como herramientas didácticas de las asignaturas.

\section{HISTORIA, MEMORIA Y CÓMIC}

Si algo caracteriza los temarios de Historia en los diferentes niveles educativos es la densidad de contenido que contrasta con la temporalidad de ejecución. Sin embargo, esto en muchas ocasiones es utilizado como elemento para no adentrarse en algunas partes del temario que algunos consideran como "espinosas", tales como la Segunda República, la Guerra Civil y el franquismo. Esto se nota cuando en los exámenes de EvAU, una parte importante del alumnado se decanta por temas relacionados con el siglo XIX o, como mucho, los primeros años del XX. Es evidente que existe un problema de tiempo, sobre todo si el Segundo de Bachillerato el curso acaba antes por la realización de las pruebas de acceso a la Universidad, pero también subyacen cuestiones metodológicas y el currículum. No deja de ser curioso que el temario de Segundo de Bachillero, tal como establece en el Real Decreto 1105/2015 de la Comunidad Autónoma de Madrid, se les preste mayor atención a los aspectos de la historia de España previos al siglo XIX, que en definitiva en el examen de EvAU representan cuatro preguntas que se tiene que explicar en no más de 10 líneas, que al siglo XX. De entrada es una asignatura mal concebida, pues se partía de hacer una Historia de España contemporánea y se introdujo todos los periodos anteriores para hacer una historia total de nuestro país.

Evidentemente no es este el espacio para plantear una alternativa general, que conllevaría cambios legislativos y organizativos de calado, pero si buscar herramientas que nos permita adentrarnos o profundizar todo lo que se pueda en aspectos que muchas veces quedan excesivamente esquemáticos o repletos de lugares comunes. Y aquí hay que unir la explicación propia del temario, la temporalidad de las unidades didácticas y la destreza del profesorado para enganchar al alumno con recursos que tenga a su alcance. El cómic, este sentido, puede jugar un factor determinante.

Para hacer una mejor exposición de lo que se quiere explicar, se va a dividir el eje temático en algunos temas (pueden ser otros) que son trasversales a los distintos niveles educativos, aunque en cada caso las actividades serían distintas:
a) Movimiento obrero
b) Mujeres y feminismo
c) Guerra Civil española
d) Fascismo, antifascismo, franquismo y antifranquismo.
e) Miscelánea 
En estas líneas se expondrá algunos ejemplos de cómic que podrían ayudar a la confección de unidades didácticas y que es lo que tratan esos materiales. Son todos libros fáciles de conseguir.

\section{Movimiento obrero}

El movimiento obrero es uno de los temas más característicos en Historia, que abarca un periodo amplio de tiempo y que se estudia en niveles de la ESO ( $4^{\circ}$ de la ESO) y en Bachillerato, siendo en Primero de Bachillerato una historia general del mismo y en Segundo el movimiento obrero en la Historia de la España. Las carencias o problemas que tiene la enseñanza del movimiento obrero ya han sido analizadas (Vadillo, 2020: 91-112).

La explicación de esta parte de la historia se suele hacer a través de textos, de recursos gráficos como películas y documentales, etc. Pero el cómic también puede jugar un papel fundamental.

En 1848 Karl Marx y Friedrich Engels escribieron un texto que revolucionaria el campo del socialismo: El manifiesto comunista. Escrito para la Liga de los Comunistas, sus textos son recurrentes a la hora de analizar el marxismo. Sin embargo, hace pocos años, apareció una versión del trascendental libro de Marx y Engels en versión manga, adaptada por Variety Artworks, donde transforma todo lo dicho en el texto clásico a través de imágenes y breves comentarios representado por una serie de personajes que defienden o critican el modelo reseñado: Bill, Frank, Norman, Bruno, Simon, etc. (Marx y Engels, 2017). De una forma sencilla se expone el concepto de la lucha de clases como motor de la historia, la conciencia obrera y la alternativa socialista al modelo industrial. La utilización de las herramientas clásicas del movimiento obrero aparece en el texto que es perfectamente utilizable en clase para profundizar en las ideas del marxismo contextualizado en la historia general del movimiento obrero.

Un acontecimiento importante y del que se ha escrito largo y tendido es la Comuna de París, que se desarrolló entre el 18 de marzo y el 28 de mayo de 1871. Muchos libros, documentales e incluso películas se han desarrollado sobre el tema. La Comuna de París ha sido llevada al cine de forma temprana en 1914 por el director anarquista Armand Guerra o de forma más reciente por Peter Watkins en el año 2000. Los trabajos de investigación sobre la Comuna de París son diversos y no faltan materiales sobre el mismo.

Sin embargo, la Comuna de París pasa por ser un elemento fundamental en la historia del movimiento obrero, al simbolizar la primera ocasión en la que el obrerismo toma posición de poder, en las que escuelas importantes del movimiento obrero como proudhonianos o blanquistas tienen su canto del cisne o la propia trascendencia del acontecimiento para el devenir del obrerismo. Una revolución que se entiende como el final del ciclo revolucionario abierto en Francia en 1789 y el punto de partida de las revoluciones obreras que marcará la historia del siglo XX. 
Un acontecimiento de estas características, aunque tiene espacio en el temario no se profundiza en él. Una buena forma de hacerlo es a través del cómic de Jacques Tardi con el título El grito del pueblo (Tardi, 2011). Existe una edición por tomos y otra en conjunto, aunque en cualquier caso sitúa el acontecimiento, los protagonistas y los debates. Cualquiera de los hechos que se quieran narrar o se quieran profundizar, las páginas del cómic son excelentes para ello. Desde el inicio de la Comuna, las posiciones de Versalles, las disposiciones revolucionarias, los protagonistas, los debates de doctrinas o la represión de la Semana Sangrienta. Un elemento que puede servir como colofón para la explicación del movimiento obrero.

Otra opción para abordar esta cuestión sería las biografías militantes de algunos integrantes del obrerismo. SI tuviésemos un bachillerato bilingüe en francés una opción sería acercarnos a dos personajes históricos a través del cómic. Uno es el fundador del periódico L'Humanité Jean Jaurès, partidario de la unidad socialista y que tiene una importante evolución desde las posiciones del republicanismo radical hasta el socialismo. En el año 2014, coincidiendo con el centenario del asesinato de Jaurès, varios autores editaron un cómic que reconstruye su vida (VVAA, 2014). En él nos muestra la evolución de Jaurès, sus debates políticos, su posición frente a la Primera Guerra Mundial y su asesinato a manos de Raoul Villain. Este cómic en francés serviría tanto para hablar del movimiento obrero tras la Primera Internacional y la consolidación de los partidos socialistas como, por ejemplo, de los debates que el movimiento obrero tuvo respecto a la Primera Guerra Mundial.

La Revolución rusa también es un acontecimiento que se imparta rodeado de muchos lugares comunes y reducida su actuación a un campo excesivamente binario: bolcheviques-mencheviques, rojos-blancos, etc. Sin embargo, fue un proceso rico en matices y, tal como Julián Casanova lo definió, un caleidoscopio de revoluciones (Casanova, 2017: 1317). Coincidiendo con el centenario en 2017 aparecieron muchas monografías sobre la revolución, reediciones de clásicos y obras de nuevo cuño que venían aportar aspectos de interés. Algo importante, más teniendo en cuenta que España no es un país donde los investigadores de Rusia proliferen. Esto llevó a que incluso cuestiones menos conocidas, y no por ellos menos importantes, del proceso como el anarquismo tuvieron en aquel año dos monografías (Taibo, 2017; Vadillo, 2017).

Y, precisamente, en esos otros aspectos de la revolución rusa se puede incidir a través de otros medios que no son los explicativos al uso y que los manuales se dejan de lado. Por ejemplo, aunque a veces se nombre, poco se conoce que en Ucrania, durante los años de la Revolución rusa, se desarrolló un modelo político, económico y social, circunscrito a la zona este del territorio, que encabezado por el anarquista Néstor Majnó, llegó a consolidar un modelo alternativo al oficial soviético y en contra de las fuerzas reaccionarias. Majnó, consolidó un Ejército Insurreccional de campesinos, que aunque llegaron a varios acuerdos con el Ejército Rojo, tuvo una estructura independiente y acabó siendo derrotado. En el año 2002, François Hambourger editó en dos volúmenes la historia del majno- 
vismo durante la Revolución rusa (Hambourger, 2002). Texto escrito en francés, que al igual que de Jaurès, podría servir como elemento de apoyo para un bachillerato bilingüe en francés. Sin embargo, esta parte de la historia se puede aplicar con un cómic de reciente aparición, aunque solo un volumen se ha traducido al castellano. Bruno Loth ha realizado un interesante cómic sobre la reunión que Durruti y Néstor Majnó tuvieron en París, en 1926, con el título ;Viva la anarquía! El encuentro entre Majnó y Durruti (Loth, 2020). En el texto, no solo se reseña lo que ambos anarquistas hablaron en aquella reunión sino que se recuerda las aportaciones de Majnó en el contexto de la Revolución rusa. Con diálogos ágiles y dinámicos se puede introducir este acontecimiento y marcar las influencias que pudo tener el revolucionario ucraniano en otro como Durruti.

En el caso español, son muchas las biografías de obreros que se han podido llevar a una aventura gráfica. Como una parte importante en estas cuestiones es profundizar en aspectos menos conocidos, un cómic que analiza la importancia del movimiento obrero a finales del siglo XIX e inicios del XX, que trata cuestiones como los modelos organizativos en las sociedades obreras y los grupos anarquistas, así como debates de interés alrededor de la Primera Guerra Mundial y la Revolución rusa, se encuentra la obra de José y Ramón Trigo Ricardo Mella. Un hombre nuevo (Trigo, 2018). Mella fue uno de los anarquistas más importantes de inicios del siglo XX sus visiones sobre la organización obrera o sus aportaciones al campo pedagógico con el concepto de la "Escuela Neutra" lo convierte en uno de los grandes olvidados que puede servir como elemento para profundizar en algunos aspectos del obrerismo.

\section{Mujeres y feminismo}

El enfoque de género y la historia del feminismo es algo inherente a currículum, ya que años de silencio condenó a la mujer a un lugar irrelevante de la historia cuando fue un sujeto protagonista sistemáticamente ocultado.

Aunque solemos marcar con mucha profusión los orígenes de la contemporaneidad y de la modernización social en la Revolución francesa de 1789, en muchas ocasiones se olvida establecer que ese fenómeno significó también el protagonismo de la mujer en el contexto revolucionario. Explicar la Revolución francesa es acercarnos al fenómeno de los derechos del hombre y del ciudadano, a los debates políticos entre grupos cada vez más definidos, las distintas etapas de la revolución, etc. Aunque la mujer si aparece no se le presta la suficiente atención para poder marcar su trascendencia. No solo por las mal llamadas tricoteuses, forma despectiva por la que fueron denominadas las mujeres en la revolución, sino por la importancia de algunas de ellas en distintos campos políticos. Desde Madame de Stäel (Anne-Louise Germaine Necker) defensora de los principios liberales avanzados de la revolución hasta Charlotte Corday, defensora del catolicismo que asesinó a Marat en la bañera. Una mujer que tiene una enorme importancia en el contexto revolucionario es Olympe de Gouges (Marie Gouzes), republicana girondina que emi- 
tió la famosa "Declaración de los Derechos de la Mujer y la Ciudadana", revindicando que no había revolución posible si no se daba completa igualdad política a la mitad de la población que carecía de ella. Este texto y su muerte como víctima del terror jacobino en su defensa de una república federal, es sobradamente conocido. Sin embargo, se puede incidir sobre ello a través del interesante cómic que se publicó en España en 2012 con el título Oympe de Gouges (Catel y Boquet, 2012). Gracias a esta obra se puede introducir a los alumnos en la personalidad de esta revolucionaria, cuyas aportaciones fueron más allá de la Declaración de los Derechos de la Mujer, ya que entroncó su lucha pionera del feminismo con el abolicionismo de la esclavitud. Algo muy en conexión con lo que sería las primeras sufragistas norteamericanas, también muy vinculadas a los movimientos abolicionistas y derechos de los negros.

Ese sufragismo, objeto de libros y películas así como con gran cantidad de material didáctico, se puede completar a la perfección con el cómic que 2015 se editó en castellano de Mary y Bryan Talbot con el título de Sufragista. Sally Heathcote (Talbot, 2015). Una buena manera, con una lectura general o seleccionando parte de la misma, de introducir la importante del movimiento que Emmeline Pankhurst o Carmen Karr desarrollaron. Se puede partir desde la explicación de las primeras feministas como Olympe de Gouges o Mary Wollstoncraft pasando por la trascendencia de la Declaración de Seneca Falls para centrar después los debates que introduce el cómic. Algo que se puede utilizar tanto para Primero de Bachillerato a la hora de hablar de los movimientos sociales o en Segundo de Bachillerato ante el debate del voto femenino en España poniendo en un contexto internacional. Es perfectamente aplicable al ámbito universitario e incluso en la primera para introducir al alumnado en la conquista de derechos.

Enganchando con el tema de la Comuna de París, se encuentra otro de los cómics de Mary y Bryan Talbot titulado La Virgen Roja (Talbot, 2016), que es la biografía de Louise Michel. Anarquista francesa y maestra, su posición fue protagonista durante la Comuna de París junto a la de la Nathalie Lemel, André Leo o Elisabeth Dmitriev. Este cómic, basado en parte en su La Comuna de París. Historia y recuerdos (Michel, 1999; Ídem, 2013 - en castellano -) reconstruye la vida de Louise Michel, sus aportaciones durante la Comuna de París, su deportación a Nueva Caledonia y su regreso a Francia donde contribuyó a la formación y extensión del movimiento anarquista organizado. Pasaje de este cómic nos pueden servir para reconstruir la participación de la mujer en los espacios revolucionarios y como fueron denostadas por la historia. Si en 1789 fueron llamadas de forma peyorativa las tricouteses, durante la Comuna de París fueron llamadas las petrouleuses (las petroleras) para vincularlas a los mayores horrores en la Comuna.

Siguiendo la dinámica de las biografías, nos encontramos la obra de Vanesa Ripio Rosa Luxemburgo. La revolución en juego (Ripio, 2019). Un curioso recorrido por la vida de esta revolucionaria alemana asesinada en 1919 y que marcó un antes y un después en el desarrollo del movimiento obrero alemán e internacional. Sus disquisiciones ideológicas así como su posición dentro de una socialdemocracia que se le iba quedando estre- 
cha, son temas centrales de esta biografía, hasta alcanzar los años de la Revolución rusa y la conformación de la Liga Espartaquista. Introducir los debates de inicios del siglo XX en el socialismo internacional a través de Rosa Luxemburgo puede ser un importante ejercicio para alumnos de niveles de secundaria y universidad. Además este texto combina las viñetas propias del cómic con un mayor desarrollo explicativo de los temas, lo que hace que sea un trabajo a caballo entre el ensayo y el cómic.

Sobre la cuestión de la mujer en relación al control de la natalidad, los métodos anticonceptivos y el nacimiento del feminismo, hay que destacar la historia de Margaret Sanger. Entre las reivindicaciones del feminismo de primera hora, estaba la necesidad de la capacidad decisoria de las mujeres a la hora de tener o no hijos y de decidir sobre su propio cuerpo. Peter Bagge realiza un interesante cómic sobre la vida de esta enfermera que titula La mujer rebelde. La historia de Margaret Sanger (Bagge, 2014). Con este cómic nos encontramos con un excelente material para introducir los debates que se van a dar en todo el mundo sobre estas cuestiones, como van a ser rechazados por los poderes establecidos y las normas sociales, bajo el influjo de la religión, y puede servir para hacer un estado de la cuestión de cómo fueron evolucionando distintos derechos que, como el divorcio o el aborto, se fueron instalando al calor de la modernización de las sociedades.

La violencia de género también ha sido objeto de estudio entre los cómics, cuestión que puede servir como complemento para unir actividades de distintas disciplinas como Historia y Filosofía. De entre los cómics desarrollados a este respecto cabe destacar el realizado por Una en 2016 con el título de Una entre muchas (Una, 2016), donde la protagonista es una niña de doce años.

Son solo un muestro de algunos temas que se pueden vincular entre el feminismo, la historia de género y el cómic.

\section{La Guerra Civil española}

La Guerra Civil española (1936-1939) sería un tema predilecto para poder enfocarlo desde didácticas diversas y muy en conexión con la memoria histórica aplicada al campo educativo.

Muchos son ya los cómics que analizan la Guerra Civil desde distintos puntos de vista, por lo que se ha convertido en una herramienta didáctica y divulgativa de primer orden para presentar o profundizar en aspectos concretos del mismo.

Para abordar una perspectiva general de la Guerra Civil, de debates que se pudieron dar en pleno proceso y de la situación de España en aquellos años, destacaríamos tres obras que son clave. En primer lugar la de José Pablo García que llevó al cómic el libro de Paul Preston La Guerra Civil española (García, 2016). El él, lo que se realiza a través de la viñeta es un exhaustivo recorrido de la historia de España previa a la Guerra Civil, los años republicanos y luego, de forma pormenorizada, todo lo que tuvo que ver con el de- 
sarrollo del conflicto bélico. El cómic da juego para diversas cuestiones, dependiendo del nivel educativo donde se quiera utilizar. Si para Segundo de Bachillerato puede ser un perfecto complemento a la hora de explicar el conflicto en su conjunto (si se realiza una lectura completa del cómic) o de aspectos concretos (divergencias entre las fuerzas leales a la República, la posición de los militares, etc.) a niveles educativos superiores se puede utilizar también como herramienta de interpretación historiográfica, situado la obra de Paul Preston.

Otro cómic muy importante para poder abordar la Guerra Civil es el de Antonio Altarriba El arte de volar (Altarriba, 2016), donde a través de las vivencias de un personaje, se repasa la historia de España del primer tercio del siglo XX (caciquismo rural, falta de oportunidades para los trabajadores, vinculación sindical, etc.). Además, el cómic, que abarca toda la vida del protagonista, diseñado en un permanente flash-back, puede servir también como testimonio de historia familiar, ya que el personaje principal de la obra es el padre del autor del cómic. En este caso la historia sirve para dar lectura a la historia de España, la Guerra Civil y el franquismo a través de la visión de un militante de la CNT, de los debates que hubo en la retaguardia y el desencanto en el exilio. Además, la historia de Altarriba que cuenta en este cómic la completa el autor con El ala rota (Altarriba, 2016) donde cuenta la historia de su madre, Petra, muy desdibujada en el primer cómic. En el caso de El arte de volar es un buen cómic para abordar los conflictos habidos entre distintas visiones de la guerra en la retaguardia republicana, para los debates doctrinales y políticos de comunistas y anarquistas o de los conceptos de militarización durante la Guerra. Como se percibían a través de los ojos de un protagonista y como se desarrollaron en la historia del conflicto.

Por último, otro de los cómics para abordar la Guerra Civil es el que nos legó Carlos Giménez en su Todo 36-39. Malos tiempos (Giménez). Este autor, del que se hará referencia en las cuestiones del franquismo, analiza de un modo particular la Guerra Civil y este completo cómic es un perfecto recurso didáctico para poder hablar del día a día de la guerra, de la vida cotidiana y de los problemas sociales y familiares que provocó el conflicto bélico.

Sobre la vida de protagonistas concretos en la Guerra Civil se puede destacar también algunos cómics de interés. Un primer ejemplo sería el de Jaime Martín Jamás tendré 20 años (Martín, 2016). El esquema es similar al seguido Altarriba, pues Martín nos narra la historia de sus abuelos, aunque en este caso la protagonista principal es una mujer, Is abel. El cómic da juego para hablar de cuestiones clave en la historia de España y en la guerra como la importancia del anarquismo, el papel de la mujer en la Guerra Civil o la fuerte represión que se vivió en la retaguardia franquista desde los primeros días de la guerra, donde Isabel perdería a todos sus amigos militantes de las Juventudes Libertarias. Como recurso didáctico, para hablar del papel de la mujer en la Guerra Civil es un muy interesante, pudieron servir para introducir temas organizativos como los de Mujeres Libres o la AMA. Un cómic muy completo, que también puede servir, en los distintos nive- 
les educativos, para hablar de la represión franquista tras la Guerra y de los campos de concentración que proliferaron en todo el territorio español en los primeros años del franquismo (Hernández de Miguel, 2019).

De protagonistas más conocidos, cabría destacar la serie que Sento hizo sobre el doctor Uriel entre 2014 y 2016. Un médico novato (2014), Atrapado en Belchite (2015) y Vencedor y vencido (2016). Se editó una obra con todos los cómics con el título Dr. Uriel (Sento, 2017). La obra de Sento nos sirve para situar a aquellos que aun simpatizando con la República y con la causa democrática se vieron atrapados en la zona sublevada y tuvieron que prestar servicios profesionales en el lugar equivocado o no deseado. Sento se basó en la obra del propio Pablo Uriel con el título No se fusila en domingo (Uriel, 2008). Temáticas como la militancia de los intelectuales y profesiones liberales en el campo republicano, la cuestión geográfica durante la guerra, el clericalismo y el anticlericalismo, la dureza de las batallas, la pena de muerte en el ejercito sublevado y el propio concepto de vencedor y vencido son temáticas trasversales a distintos niveles educativos.

Si estuviésemos ante un bachillerato bilingüe en francés, un texto realmente interesante que rescata la vida de Gerda Taro y Robert Capa es Tristes Cendres (Begoña e Iñaket, 2011). Un cómic en francés que nos sirve para recuperar la participación extranjera en la Guerra Civil, la simpatía de los intelectuales extranjeros con la República en el conflicto bélico así como la dimensión de internacional e informativa que tuvo la Guerra Civil en todo el mundo. La figura de Gerda Taro como mujer en la primera línea de frente, que va a morir durante la batalla d e Brunete o la labor del fotoperiodismo, son ejes didácticos que se pueden trabajar en el aula con este cómic.

Las cuestiones del ejército, las milicias y los debates que se dieron en la retaguardia republicana de como afrontar el conflicto, son temas centrales en algunos cómics. Un clásico, realizado en la temprana fecha de 1979, es Eloy (Hernández Palacios, 1979). Un nombre para un participante en la Guerra Civil donde aparecen toda una cohorte de personajes reales tales como Enrique Lister, Vicente Rojo o Buenaventura Durruti. Mas específico es la aportación de Bruno Loth titulada Los fantasmas de Ermo (Loth, 2013), que cuenta la historia en tres volúmenes del huérfano Ermo, que se une al anarquismo y la lucha que se inicia en España con el golpe de Estado contra la República. Un texto que sirve para mostrar las divergencias que había en la retaguardia republicana. Con mayor o menor lugares comunes, este tipo de materiales pueden ser un buen punto de partida para hablar de estas cuestiones.

Sobre el sentimiento de desarraigo en el conflicto, la pérdida de valores o las vidas individuales destruidas, de una vida cotidiana que acabó pulverizada, nos volvemos a remitir a la obra de Paco Roca con El Faro (Roca, 2011). Una historia simple de un carabinero republicano, muy joven, que ve como su futuro se rompe por la derrota en la Guerra Civil y como un farero llamado Telmo le hará que sus ganas de salir adelante vuelvan a brotar. Un comic que nos puede servir para abordar lo relacionado con la parte más intima de la derrota republicana. 
Son solo una muestra de varios ejemplos de cómic para poder abordar la Guerra Civil desde diferentes puntos de vista.

\section{Fascismo, antifascismo, franquismo y antifranquismo}

Durante de la década de 1920, 1930 y 1940, Europa y el mundo fue testigo del avance de los totalitarismos, representados por el fascismo, el nazismo y franquismo entre otros. Lo que supusieron aquellos regímenes, sus consecuencias y capacidad represiva han sido ampliamente tratados por la historiografía en trabajos generales y algunos específicos sobre el tema.

Sin embargo, el cómic también ha abordado estas cuestiones, y aquí se van a consignar algunos de los títulos al respecto. Teniendo en cuenta la adaptación del concepto de memoria histórica a España, el franquismo y el antifranquismo será de mayor atención.

El nacimiento del nazismo es un tema perfectamente tratado por Maus (Spiegelman, 2000). Este cómic es un recurso didáctico de primer orden, pues puede incluso pasar por un manual sobre la persecución al pueblo judío y el Holocausto provocado por los nazis. El avance del nazismo por Europa, la conquista de territorios que iba aparejada a la persecución y exterminio del pueblo hebreo, lo cuenta Spiegelman. No deja de ser una historia personal del autor, de sus padres y también de su pueblo. Perfectamente contada, cada grupo de personajes se adapta a un animal. El propio título ya marca a los protagonistas, ya que "maus" en alemán es ratón, y los judíos están representado como ratones. Los alemanes son los gatos (el gato y el ratón), los polacos son cerdos, los americanos perros, los franceses ranas, los suecos ciervos y los británicos peces. Un alegato contra el racismo del nazismo y en defensa del pueblo judío, contada de forma sencilla que sirve como recurso didáctico inmejorable para esta parte de la historia. Además, en el caso de la CAM, puede jugar un papel importante dentro de la importancia que el currículum le da a la persecución hebrea durante la dictadura nazi.

En este sentido Maus ha sido un reflejo para muchos otros autores. Sobre las cuestiones generales de la Segunda Guerra Mundial, hay que destacar la reciente obra de Eugenia Anglés, basada en la obra homónima Antony Beevor, titulada La Segunda Guerra Mundial. Una historia gráfica (Anglés, 2020). De una forma sencilla y amena nos adentra en una historia total de este acontecimiento histórico con cuestiones clave como el antifascismo y el antinazismo incluido en sus páginas.

Sin embargo, vamos a centrar la atención en el mundo del franquismo y del antifranquismo. El franquismo ha sido objetivo de estudio en numerosos cómics, por lo que aquí tan solo vamos a hacer un muestreo.

Un primer aspecto a destacar sería la lucha de los españoles contra el fascismo en $\mathrm{Eu}$ ropa, cuestión menos conocida y que con el paso del tiempo va tomando cuerpo. Aquí destacamos dos obras básicas. En primer lugar, la del polifacético Paco Roca y Los surcos 
del azar (Roca, 2013) que cuenta la historia de La Nueve, la unidad que combatió dentro del Ejército francés y que fue la primera compañía que entro en París en agosto de 1944. Las imágenes de los blindados con los nombres de "Guadalajara", "Brunete", "España cañí, etc., y con los emblemas republicanos y antifascistas, es una de las imágenes de la derrota nazi en Europa. Sin embargo, tanto en Francia como en España su actividad no ha sido reconocida hasta hace poco tiempo, lo convierte a esta obra de Roca en un eje básico educativo para mostrar al alumnado la importancia de este grupo de españoles, entre otros muchos combatientes, en la Segunda Guerra Mundial al lado de las fuerzas aliadas.

El segundo de los textos que destacamos en esta línea sería el de Jordi Peidro Esperaré siempre tu regreso (Peidro, 2016), que cuenta la historia de un militante de la CNT, combatiente en la Guerra Civil, que en los primeros años del exilio estuvo recluido en el campo de concentración de Mauthausen y completo su ciclo de lucha en el exilio francés. AL igual que en el de Paco Roca, es interesante destacar la enorme actividad que tuvieron los anarquistas exiliados en la lucha con el fascismo en aquellos años. Se puede mostrar al alumnado aquel exilio en el contexto general de los republicanos perseguidos, pero se puede hacer un mapa de las distintas ideologías y grupos políticos para ver el enorme mosaico que fue la derrota republicana.

Entrando en el franquismo y su día a día, podemos destacar algunos cómics que pueden servir para presentar el tema o enmarcar cuestiones concretas. Un clásico es el de Carlos Giménez Todo Paracuellos (Giménez, 2007). En realidad, el texto lo presentó Giménez por partes hasta que se hizo un volumen con todo. Una visión de la España franquista bajo los ojos del propio autor como protagonista, en un hogar de la Obra Nacional de Auxilio Social. El desarraigo, el hambre, etc. El texto se puede utilizar como una historia de esa parte del franquismo y también se puede utilizar la intrahistoria del texto, de las dificultades que Carlos Giménez tuvo para poder darlo a conocer y como se valió de medios en la Transición democrática como Muchas Gracias, El Papus o Yes. Sirve, por lo tanto, para mostrar un espacio mucho más amplio de esta historia.

El hambre, también tratado por Giménez, es abordado también por Alfonso López en El Solar (López 2016). Un preso del campo de concentración de Miranda de Ebro, que es liberado, y vuelve a "reinsertase" en una sociedad que no facilita nada a aquellos que habían defendido la legalidad republicana. Además, López hace numerosos guiños en su obra a personajes del cómic, pues el protagonista es un trasunto de Carpanta. Con un tono de humor y, al mismo tiempo, ese trasfondo trágico, la obra de López es buen ejemplo para trabajar la falta de oportunidades de los derrotados en la Guerra Civil en los años de plomo del franquismo.

Las caras de la represión fueron múltiples durante el franquismo, y muchos profesores, maestros, periodistas y otras profesiones, no pudieron ser ejercidas por aquellos que habían sido derrotados y depurados por las autoridades triunfantes. Ejemplos de periodistas y escritores como Eduardo de Guzmán, que no podían firmar sus artículos o malvivían con historias que firmaban bajo seudónimo. Parte de esas historias nos la cuenta, 
una vez más, Paco Roca en El invierno del dibujante (Roca, 2016), donde un grupo de escritores y dibujantes tardan años en volver a poder ejercer su profesión debido a sus ideas políticas democráticas. Algo menos trabajo en la historiografía y que podría ser ejemplo de un reflejo de ese prisma de la represión.

Por último, no se puede olvidar el papel que jugaron las mujeres, doblemente reprimidas cuando habían defendido la legalidad republicana, y mayormente olvidadas por la historia. Ya se ha hecho referencia más arriba a esta circunstancia, con el libro de Altarriba El ala rota, dedicado a su madre Petra, y que había quedado en un segundo plano en El arte de volar. Sin embargo, para la cuestión de la represión de las mujeres, un buen ejemplo de cómic puede ser Cuerda de presas (García y Martínez, 2017). Publicado en 2005 ha tenido varias reediciones. Su estructura ayuda mucho a afrontar una actividad didáctica en esta línea, pues son once historias cortas de la represión que el franquismo ejercicio contra las mujeres, la vida cotidiana, la explotación laboral, las prisiones, etc.

La otra obra sobre la mujer a destacar para poder aplicar a la didáctica sería el Estamos todas bien (Penyas, 2017). Una vez más, basado en la historia familia, Anna Penyas habla de la historia de sus dos abuelas y de los problemas que la mujer, desde distintos puntos de vista, tuvieron en el franquismo.

La vida militante también ha sido objeto del cómic en este aspecto de la resistencia contra el franquismo. Aunque hay muchos títulos que pudieran valer al efecto destacaría dos. El primero el de Alfonso López con el título Miguel Núñez. Mil vidas más (López, 2010), que cuenta la historia de este militante comunista que tuvo una intensa vida de lucha contra el franquismo y por el regreso de las libertades democráticas a España. Otro sería el de Belatz con el título El tesoro de Lucio. Una novela gráfica sobre Lucio Urtubia (Belatz, 2018). Cuenta de la vida de Lucio Urtubia, anarquista militante que tuvo un importante papel en la lucha antifranquista.

Cabe destacar también algunos episodios poco trabajados u olvidados en la historia del franquismo, como fue los problemas en el Marruecos colonias y la guerra del Sidi Ifni. Aunque recientemente apareció la obra de Gustavo Ordoño La guerra del Ifni (Ordoño, 2018), el cómic también ha abordado el problema con la obra de Jaime Martín Las guerras silenciadas (Martín, 2014)

El franquismo es uno de los temas que más títulos a este respecto está deparando el cómic.

\section{Miscelánea}

Aquí se han abordado los principales ejes de estudios, pero todos y cada uno de los aspectos de la historia se podía asimilar con un cómic.

La Transición democrática también tiene títulos que puede ayudar a entenderla o para debatirla en clase. Rubén Uceda, que ha trabajado también cuestiones de la Guerra Civil, 
publicó en 2018 Atado y bien atado (Uceda, 2018), que analiza de una forma crítica el proceso de Transición democrática. Lo interesante del cómic de Uceda es que los protagonistas del mismo no son los principales actores que se consignan en los libros de texto, sino que son los obreros, las mujeres, los movimientos vecinales, los quinquis, los militantes revolucionarios, los presos comunes, etc. Una manera de poder introducir esa otra Transición o presentar los problemas estructurales de España tras la muerte de Franco.

Si para la Segunda Guerra Mundial se ha citado la obra de Anglés, para la Primera Guerra Mundial es parada obligatoria la obra de Tardi ¡Puta Guerra! (Tardi/Verney, 2010). Aunque fue publicada por parte, hay versiones integrales que facilitan su utilización como recurso didáctico.

Los problemas actuales también pueden ser enfocados desde el cómic. La revolución iraní de 1979 tiene un buen ejemplo de recurso didáctico en Persépolis (Satrapi, 2007). Corea del Norte puede ser abordado con la obra de Guy Delisle Pyongyang (Delisle, 2015). O cuestiones como Palestina, crímenes en la guerra de Yugoslavia, los problemas de África, etc., se encuentran en la amplia obra de Joe Sacco: Reportajes (2012), Notas al pie de Gaza (2010), Historias de Bosnia (2016), Días de destrucción, días de revuelta (2015), Palestina (2015), Un tributo a la tierra (2017).

El cómic es una parte fundamental de los recursos didácticos para la historia en todos los niveles.

\section{ACTIVIDADES}

Las actividades a desarrollar con estos recursos didácticos pueden ser variadas y se tienen que adaptar según al nivel que estemos enfocando. No puede ser el mismo grado de exigencia en una actividad de primaria que de secundaria o universidad.

Un primer paso sería programar dentro de la actividad docente alguna de estas actividades. Se tendrá que pensar si se va a mandar leer un cómic completo o bien se van a utilizar extractos de algunos para distintas partes de la historia.

Posteriormente se tendrá que decidir que tipo de actividad, que pueden ser variadas y complementarias: trabajos en grupo, fichas de lectura, etc.

También se pueden organizar vidas familiares, y que los alumnos y alumnas realicen encuestas en su entorno familiar para sondear los conocimientos o las vivencias sobre alguno de los aspectos tratados.

Una parte fundamental es la utilización de la TIC. Aunque siempre se puede presentar el clásico trabajo escrito, hay otras modalidades que pueden ser recursos interesantes. La confección de un programa de radio con la elaboración de podcast, lo que nos puede valer para ejercer un modelo de trabajo cooperativo. También existen aplicaciones para poder realizar periódicos, además perfectamente adaptables a las enseñanzas bilingües. Un 
ejemplo sería www.flipsnack.com que permite la elaboración de periódicos. También poder confeccionar un blog (mas sencillo en blogger.com o más complejo en wordpress.com)

Un recurso a utilizar, en el caso de los Institutos o incluso Universidades, sería la trasversalidad de algunos temas. Analizar a figuras de historia que al mismo tiempo formaron parte del ámbito literario, puede servir para ejecutar planes comunes en asignaturas como Historia y Lengua y Literatura. O los espacios geográficos que pudiera ocupar el exilio o cualquier acontecimiento tratado, que una las actividades de Historia y Geografía.

Un buen diseño de actividades puede servir para marcar un inicio de aplicación de la memoria histórica al campo educativo. Algo necesario para el alumnado, pero también para el docente, que tendrá que hacer cursos de formación en esta línea o la petición en las Facultades de Formación del Profesorado de asignaturas o máster en esa línea.

\section{REFERENCIAS}

ALTARRIBA, Antonio (2016): El arte de volar, Barcelona: Norma editorial.

Ídem (2016): El ala rota, Barcelona: Norma editorial.

ANGLES, Eugenia (2020): La Segunda Guerra Mundial. Una historia gráfica, Barcelona: Pasado \& Presente.

ARROYO DÍAZ, Elena (2019): El cómic como recurso didáctico para el estudio de la Historia Contemporánea. Selección de lecturas para ESO y Bachillerato, Universidad de Castilla-La Mancha.

BAGGE, Peter (2013): Mujer rebelde. La historia de Margaret Sanger, Barcelona: La Cúpula.

BEGOÑA, Mikel e Iñaket (2011): Tristes cendres, Paris: Cambourakis.

BELATZ (2018): El tesoro de Lucio. Una novela gráfica sobre la vida de Lucio Urtubia, Tafalla: Ed. Txalaparta.

CASANOVA, Julián (2017): La venganza de los siervos. Rusia 1917, Barcelona: Crítica.

CATEL y BOQUET (2012): Olympe de Gouges, Madrid: Sins Entido.

COLLADO CERVERÓ, Francisco (s/f): Los del monte. Una historia del maquis, FCC editor. 
DE ARRIBA, David F. (2019): Memoria y viñetas. La memoria histórica en el aula a través del cómic, Valencia: Desfiladero ediciones.

DESLISLE, Guy (2015): Pyongyang, Bilbao, Astiberri.

DÍEZ GUTIÉRREZ, Enrique Javier y RODRÍGUEZ GONZÁLEZ, Javier (2008): Unidades didácticas para la recuperación de la Memoria Histórica, León: Foro por la Memoria de León.

ESCRIVÁ MOSCARDÓ, Cristina (2009): Guía didáctica. Los Institutos para obreros. 1936-1939, Valencia: L'Eixam edicions.

ESCRIVÁ, Cristina y MAESTRE, Rafael (2008): Guía didáctica. La Revolución Libertaria. 19 de julio de 1936, Valencia: Confederación General del Trabajo.

FLORES TRISTÁN, Francisco (2007): La escuela de la Segunda República, Madrid: Fundación de Investigaciones Educativas y Sindicales - CCOO.

GARCÍA, Jorge y MARTÍNEZ, Fidel (2017): Cuerda de presas, Bilbao: Astiberri.

GARCÍA, José Pablo (2016): La Guerra Civil española, Barcelona: Debate.

GIMÉNEZ, Carlos (2007): Todo Paracuellos, Barcelona: Debolsillo.

Ídem (2011): Todo 36-39. Malos tiempos, Barcelona: Debolsillo.

GIRAL, Antoni (2008): Los tebeos de nuestra infancia, la escuela Bruguera 1964-1986, Barcelona: Edicions El Jueves.

HAMBOURGER, François (2002): Makhno. L’Ukraine libertaire, 1918-1921, Paris : Ed. Le Monde Libertaire.

HERNÁNDEZ DE MIGUEL, Carlos (2019): Los campos de concentración de Franco, Barcelona: Ediciones B.

HERNÁNDEZ PALACIOS, Antonio (1979): Eloy, uno entre muchos, Vitoria: Ikasager.

HERNANDEZ SÁNCHEZ, Fernando (2016): El bulldozer negro del general Franco. Historia de España en el siglo XX para la primera generación del XXI, Barcelona: Pasado \& Presente.

LAPORT, Sophie (2016): Hergé, Paris: Edicions Moulissanart.

LÓPEZ, Alfonso (2010): Miguel Núñez. Mil vidas más, Alicante: Edicions de Ponent.

Ídem (2016): El Solar, Barcelona: La Cúpula.

LOTH, Bruno (2013): Los fantasmas de Ermo, Madrid: Ed. Kraken.

Ídem (2020): ¡Viva la anarquía! El encuentro entre Majnó y Durruti, Madrid: Los Libros de la Catarata.

MARTÍN, Jaime (2014): Las guerras silenciosas, Barcelona: Norma editorial. 
Ídem (2016): Jamás tendré 20 años, Barcelona: Norma editorial.

MARTÍNEZ MARTÍN, Antonio (1968): "Apuntes para una historia de los tebeos III. Tiempos heroicos del tebeo español (1936-1946)" en Revista de Educación, numero 196, Madrid.

MARX, Karl y ENGELS, Friedrich (2017): El manifiesto comunista, Barcelona: La otra H. MOIX, Terenci (2007): Historia social del cómic, Barcelona: Bruguera.

ORDOÑO MARIN, Gustavo Adolfo (2018): La Guerra de Ifni. Cuando la Guardia Mora abandono a Franco, Córdoba: Almuzara.

PEIDRO, Jordi (2016): Esperaré siempre tu regreso, Valencia: Ediciones Desfiladero.

PENYAS, Ana (2017): Estamos todas bien, Barcelona: Salamandra.

RIPIO, Vanesa (2019): Rosa Luxemburgo. La revolución en juego, Madrid: Akal.

ROCA, Paco (2011): El Faro, Barcelona: Norma editorial.

Ídem (2013): Los surcos del azar, Bilbao: Astiberri.

Ídem (2016): El invierno del dibujante, Bilbao: Astiberri.

SACCO, Joe (2010): Notas al pie de Gaza, Barcelona: Reservoir books.

Ídem (2012): Reportajes, Barcelona: Reservoir books.

Ídem (2015): Días de destrucción, días de revuelta, Barcelona: Planeta.

Ídem (2015): Palestina, Barcelona: Planeta.

Ídem (2016): Historias de Bosnia, Barcelona: Planeta.

Ídem (2017): Un tributo a la tierra, Barcelona: Reservoir books.

SATRAPI, Marjane (2007): Persépolis, Barcelona: Norma editorial.

SENTO (2018): Dr. Uriel, Bilbao: Astiberri.

SPIEGELMAN, Art (2000): Maus, Barcelona: Reservoir books.

TAIBO, Carlos (2017): Anarquismo y revolución en Rusia, 1917-1921, Madrid: Los Libros de La Catarata.

TALBOT, Mary M y Bryan (2015): Sufragista. Sally Heathcote, Barcelona: La Cúpula Ídem (2016): La Virgen Roja, Barcelona: Penguin Ramdom House.

TAPIA VÉLEZ, Alba (2018): El cómic como recurso didáctico. Una propuesta interdisciplinar desde la plástica, Santander: Universidad de Cantabria.

TARDI, Jacques (2011): El grito del pueblo, Barcelona: Norma editorial.

TARDI, Jacques y VERNEY (2010): ¡Puta guerra! 1914-1919, Barcelona: Norma ediciones. 
TRIGO, José y Ramón (2018): Ricardo Mella. El hombre nuevo, Autoedición.

UNA (2016): Una entre muchas, Bilbao: Astiberri.

VADILLO MUÑOZ, Julián (2017): Por el pan, la tierra y la libertad. El anarquismo en la Revolución Rusa, Guadalajara: Volapük ediciones.

Ídem (2019): "Memoria histórica. Concepto desde la historiografía y los movimientos sociales" en Actas de las I Jornadas de Historia Democrática "Participación con memoria, Córdoba: Diputación de Córdoba.

Ídem (2020): "El tratamiento del movimiento obrero en los manuales de Historia del Mundo Contemporáneo" en Didácticas Específicas, número 23, Universidad Autónoma de Madrid.

UCEDA, Rubén (2018): Atado y bien atado, Madrid: Akal.

VILCHES, Gerardo (2019): "Una breve historia del cómic" en DE ARRIBA, David F. (2019): Memoria y viñetas. La memoria histórica en el aula a través del cómic, Valencia: Desfiladero ediciones.

VV.AA. (2014) : Jaurès, París : Fayard. 